\title{
PROPERTY DATABASE FOR THE DEVELOPMENT OF SHAPE MEMORY ALLOY APPLICATIONS
}

\author{
W. TANG, J. CEDERSTRÖM*and R. SANDSTRÖM \\ Department of Materials Technology, The Royal Institute of Technology, S-100 44 Stockholm, Sweden \\ *Scandinavian Memory Metals AB, Box 52, 13321 Saltsjöbaden, Sweden
}

\begin{abstract}
Important points involving the selection of shape memory alloy (SMA) application projects are discussed. The development of a property database for SMA is initiated. Both conventional data as well as characteristics which are unique for SMA are stored. As an application example of the database SMA-SELECT, important properties for Ti-Ni alloys near equi-atomic composition, such as temperature window width for superelasticity (SE), stress rate, critical yield stress, and their interaction have been analysed together with the influence of Ni content and heat treatment conditions. SE behaviour of Ti-Ni SMA is directly related to Ni content. Thermo-mechanical treatment affects SE by changing microstructure which in turn alters the critical yield stress and stress rate. The advantage of the database has been demonstrated when assessing experimental data of complex nature.
\end{abstract}

\section{Introduction}

Twenty years have past since people first tried to find applications for shape memory alloys (SMA). So far, SMA have not been widely used in comparison with other engineering materials, although great efforts have been put into the exploration of applications. A survey indicates that less than $2 \%$ of patents for applications of SMA are matched by products actually being sold in any appreciable quantities. It is evident that too many development programs have been carried out without due consideration of the relevance for advanced materials in general ${ }^{[1]}$ and SMA in particular.

Generally, product development is initiated by or at least in close cooperation with marketing management. There are signs that this practice is entering also the SMA field, but in the past this has not often been the case. An impressive amount of work has been done by scientists and engineers without sufficient support from the marketing profession. Consequently, few developed SMA applications have been presented to the market in a professional way. Commitment from the marketing department or from a customer that is willing and able to fund the development cost and to carry out the marketing is important.

In science it is sometimes claimed that an achievement comes about because it is possible. This is not a sufficient criterion for product development. A number of projects have been started because it was possible to achieve a brilliant design, solve a problem in a spectacular way or create an entirely new function. It is essential that the envisaged product has a wide margin of superiority technically and/or economically. The reason why so few SMA applications replacing bi-metals are marketed is probably that the SMA technology has not been able to offer a good enough combination of superior qualities. Without that, the market, which is essentially quite conservative, will be reluctant to accept any changes.

There is a danger in working with a new technology. Enthusiasm can make one blind. One of the authors has been close to deciding upon technical solutions involving SMA but in the course of the 
projects found out that other technology was better. It is not sound business policy to invest in developing products that run the risk of soon being replaced by superior alternatives. One can often see that a product that has been on the market for a long time can be improved. Improved and new materials, better manufacturing techniques etc. have evolved. The fact that advantages may be gained by introducing a SMA design does not mean that it is the best design.

Some development projects do not in the end quite comply with the technical requirements. Published data for SMA engineering properties must be used with care. In our experience design goals should be set considerably lower than maximum figures for e.g. recoverable strain. If it is not possible to draft a design using about $1 / 2$ of the SME performance as published, future problems may be avoided by choosing another project. The nature of SMA properties and their performance dependence on thermo-mechanical history requires thorough understanding to develop products requiring precision performance. SMA have numerous unique properties which also depend on the external conditions. Access to sufficient and reliable property data is a central problem. It is important to develop a property database to make property data more readily accessible.

Different from most traditional engineering materials, properties for SMA have to be considered as a function of temperature, strain (or stress), and time. This has to be taken into account when representing properties in a database. Many property databases are now in existence for engineering materials. ${ }^{[2]}$ Most of these databases cover conventional materials like plastics and steels. The typical situation is that a large number of materials is included in each database. For SMA on the other hand only a limited number of alloys is of engineering interest. However, for each alloy many properties and their parameter dependence have to be handled in order to make the database useful. The purpose of the present paper is to describe the database SMA-SELECT which is presently under development. The aim is also to establish contacts with bodies having interest in participating in the development of the database.

\section{Description of the database}

As database management system PC-dBASE is used. This enables an easy transport to other PC:s so that any one interested in the system can use it. At present the database contains approximately 90 fields covering both conventional information available in any experimental materials database as well as more specific information only of relevance for SMA.

The conventional part includes information on batches, compositions, tests series, thermo-mechanical treatment, specimen, descriptors, and basic properties at room temperature. ${ }^{[3]}$ Batch information consists of batch identifier, batch number, material group, metallurgical process, producer etc. Batch number is specified by the company which has produced the batch and this company is listed as producer. If experimental data are from open literature, sources are presented. There is a text providing exhaustive specification for the material batch if necessary. Each batch of material may have one or more test series. Test set offers information on dataset, working process, product form, testing method, testing machine and laboratory. Specimen data, such as dimension, preparation technique, measuring direction, are collected in the database. Data set, as a key field, are based on the thermo-mechanical treatment condition as shown in Table 1.

Experimental data for SMA are collected on transformation temperature and microstructure, deformation behaviour associated with free recovery and superelastisity (SE), constrained recovery, thermal cycling at constant load, thermal cycling at constant strain, work output, stress cycling effect, two-way SME training, and high-temperature applications. The descriptors on SMA included in the database are based on books, ${ }^{[4,5]}$ as well as introductory articles and reviews on SMA. At the present time, experimental information on the mechanical properties and SME as well as SE behaviour of Ti-Ni alloys are collected mainly from the open literature. Information concerning transformation temperatures, $M_{s}, M_{f}, A_{s}, A_{f}$, and $R$-phase (rhombohedral phase) transition temperature $T_{R}$ are available together with microstructure and internal structure (e.g. second phase, dislocation structure).

Tensile stress-strain curves at various temperatures indicate the deformation behaviour associated with 


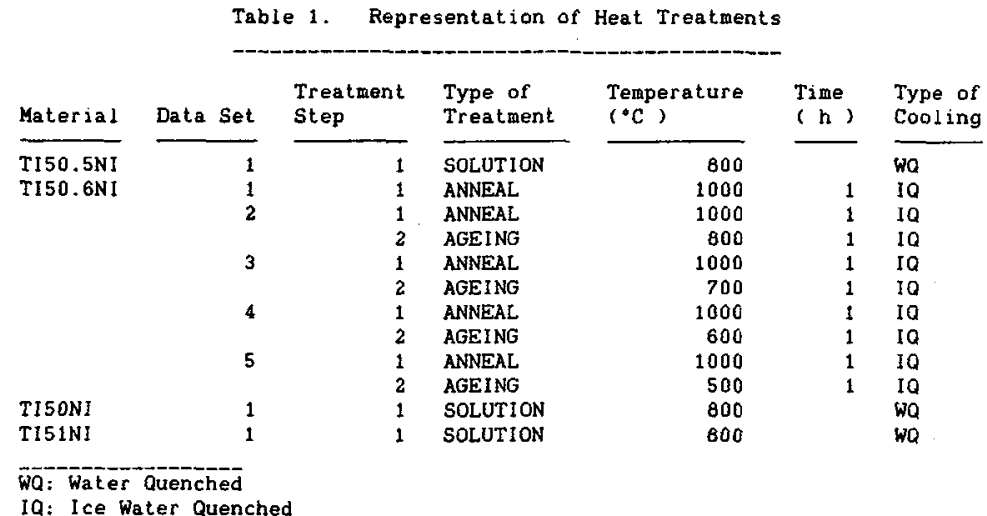

SME and SE. Yield stress, total stress range, total strain range, apparent plastic strain, final strain (after heating), and the shape recovery amount are given. Other descriptors, such as stress rate, critical yield stress for parent phase, can be evaluated from the dependence of the quantities above on deforming temperatures. It should be mentioned that the tensile stress-strain curves change greatly at different test temperatures due to the characteristics of thermal and stress induced transformations of SMA. Different ways have been used to determine the yield stress from the shape of the curve. In some cases yield stresses at both 0.2 and $1.0 \%$ strain have been collected.

\section{Assessment of results and discussion}

It is well known that the deformation mode of SMA strongly depends on the temperature. For $\mathrm{Ti}-\mathrm{Ni}$ alloys starting from high temperature (austenitic state) down to temperature $T$, the deformation behaviour can be usually divided into four regions: i) $T<M_{s}$; ii) $M_{s}<T<A_{f}$; iii) $A_{f}<T<T_{c}$; iv) $T>T_{c}$; here $T$ is the test temperature and $T_{c}$ the critical temperature at which the plastic slip starts. Each region corresponds to its particular tensile stress-strain curve. As a result, the yield stress varies with the testing temperature greatly. The characteristic feature of the temperature dependence of the yield stress is shown as Fig.1. ${ }^{[6]}$ Most experimental data for Ti-Ni SMA taken from different sources show the same tendency as in Fig. 1 independent of the $\mathrm{Ni}$ content and the heat treatment conditions. The yield stress takes its minimum value around the $M_{s}$ temperature, indicating the low strength of martensite. When $T<M_{s}$, the yield stress decreases with increasing temperature because the deformation proceeds in this range due to the reorientation of martensite variants and the migration of internal twin boundaries, which are affected by the thermal activation process. In region (ii) $\left(M_{s}<T<A_{f}\right)$, the deformation is associated with the formation and growth of stress-induced martensite (SIM). The critical stress for inducing martensite rises with increasing temperature. The linear part of the curve $\left(A_{f}<T<T_{c}\right)$ has a deformation mode which is almost the same as that of range (ii), but SIM is no longer stable after stress is removed, leading to superelasticity. The relation between the critical stress and deformation temperature can be determined by the Clausius-Clapeyron equation ${ }^{[7]}$

$$
\frac{d \sigma}{d T}=\frac{\Delta H}{T_{0} \Delta \varepsilon}
$$

where $d \sigma / \mathrm{dT}$ indicates the temperature dependence of the critical stress for the transformation at $A_{f}<T<T, \Delta H$ is the enthalpy of transformation, $\Delta \varepsilon$ is the strain associated with the transformation, and $T_{0}$ is the equilibrium temperature between the martensite and the austenite. Therefore, the slope of the linear part represents one of the most important properties for SMA-the stress rate. In the temperature interval $\left(A_{E}<T<T_{c}\right)$ superelasticity occurs. This temperature range is hence referred to as the temperature window width of SE in which almost complete SE exists. Since $T_{c}$ is the critical 


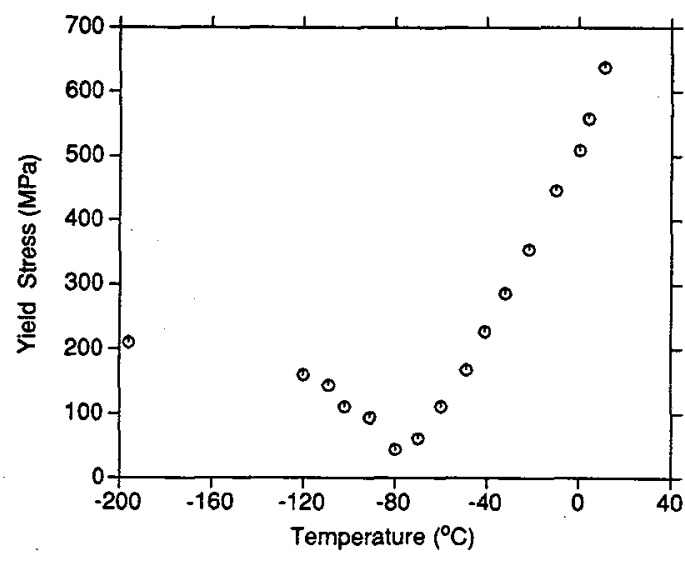

Fig. 1 Yield stress as a function of temperature for a Ti-Ni alloy

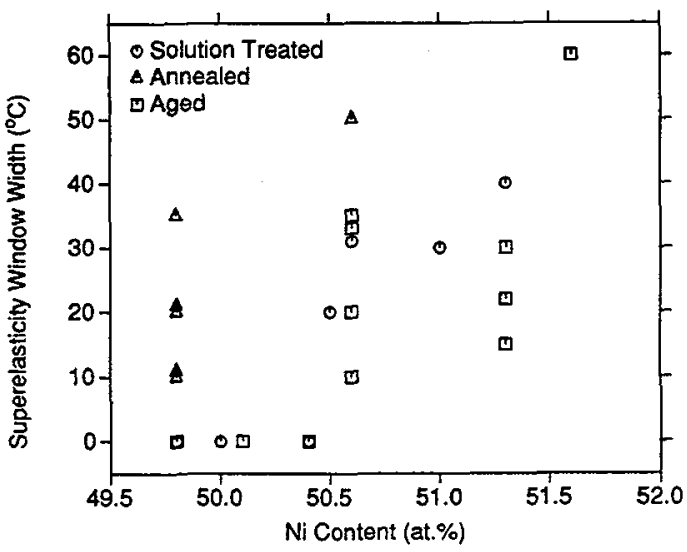

Fig.2 Dependence of superelasticity temperature window width on Ni content

temperature at which plastic deformation of parent phase by dislocation movement starts, it is the transition point to the range (iv) where the critical stress deviates from a linear relation. The stress corresponding to $T_{c}$ can be considered as the lower limit of yield strength $\sigma_{p}$ for parent phase. In range (iv) most experimental data show an upwards deviation, whereas some give a downwards deviation. ${ }^{[4]}$ The reason is unknown.

Important properties according to the discussion above for SMA such as yield stress, stress rate, and SE temperature window width are stored in the database. Experimentally they can be obtained from a series of tensile stress-strain curves. As an example, results for Ti-Ni alloy near equi-atomic composition were chosen to be analysed due to their importance for practical applications.

In Fig.2 the SE temperature window width is plotted versus Ni content. Each point represents a test series. 50.5 at.\% Ni can be considered as a line of demarcation. The window width of SE is zero for a Ni content less than 50.5 at.\% after solution or ageing treatment. This means that these alloys have the SE property only after annealing treatment. When $\mathrm{Ni}>50.5$ at.\%, the window width of SE increases with increasing Ni content for all three treatments. It shows that ageing has no effect on the lower $\mathrm{Ni}$ content specimen. This can be explained by the Ti-Ni phase diagram. Some secondary phases such as $\mathrm{TiNi}_{3}$ and $\mathrm{Ti}_{42} \mathrm{Ni}_{58}$ precipitate on the Ni-rich side of the diagram ${ }^{[8]}$ during ageing. Fine precipitates affect the flow stress for slip and thus the SE behaviour. Experimental data for 50.6 at.\% Ni taken from ref.[9] indicate that $400^{\circ} \mathrm{C}$ annealing after cold work gives the highest window value of $50^{\circ} \mathrm{C}$, and among the ageing treatments the $400^{\circ} \mathrm{C}$ ageing after a $1000^{\circ} \mathrm{C}$ solution gives the best result. However, for 51.3 at.\% Ni content, another source ${ }^{[10]}$ demonstrates that solution treatment $\left(1000^{\circ} \mathrm{C}\right.$ for $\left.1 \mathrm{~h}, \mathrm{WQ}\right)$ yields the best effect compared with ageing treatments. It can be concluded that, for high Ni content $(>50.5$ at.\%), the best treatment condition is dependent on the alloy composition, but the trend exists that $\mathrm{SE}$ behaviour is improved with $\mathrm{Ni}$ content increasing for all heat treatment conditions; when $\mathrm{Ni}$ content is less than $\mathbf{5 0 . 5}$ at.\%, only annealing after cold work yields the SE behaviour and other treatments such as ageing have no effect.

Fig.3 shows that the high Ni content batches have in general a high critical yield stress $\sigma_{\mathrm{p}}$ for specimens treated by solution or ageing. For 49.8 at.\% Ni annealing at $400^{\circ} \mathrm{C}$ can improve the $\sigma_{\mathrm{p}}$ to as high as 625 $\mathrm{MPa}$. This gives the reason why annealing after cold working can induce SE behaviour even for Ni contents lower than 50.5 at.\%. Fig.4 clearly indicates a relationship between $\sigma_{\mathrm{p}}$ and the window width for SE: for $\sigma_{p}<300 \mathrm{MPa}$, almost no batch has SE behaviour; whereas batches with the highest window width of SE correspond to a stress level of about $600 \mathrm{MPa}$. 


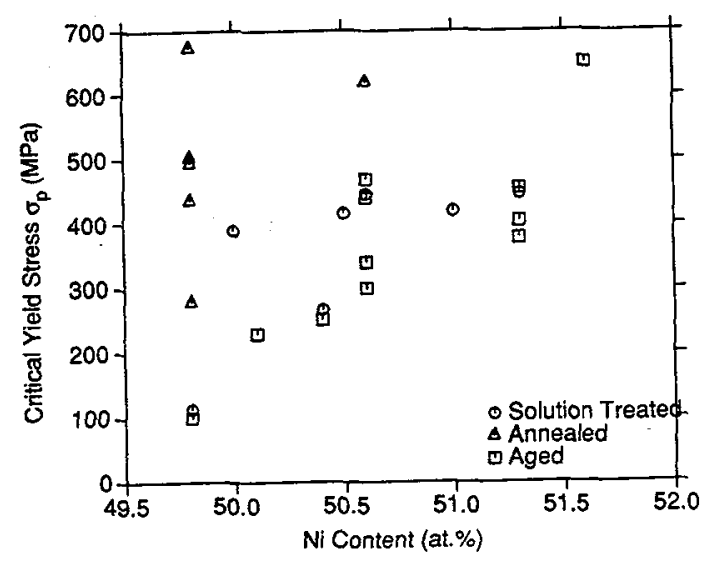

Fig.3 Dependence of criticai yield stress on Ni content

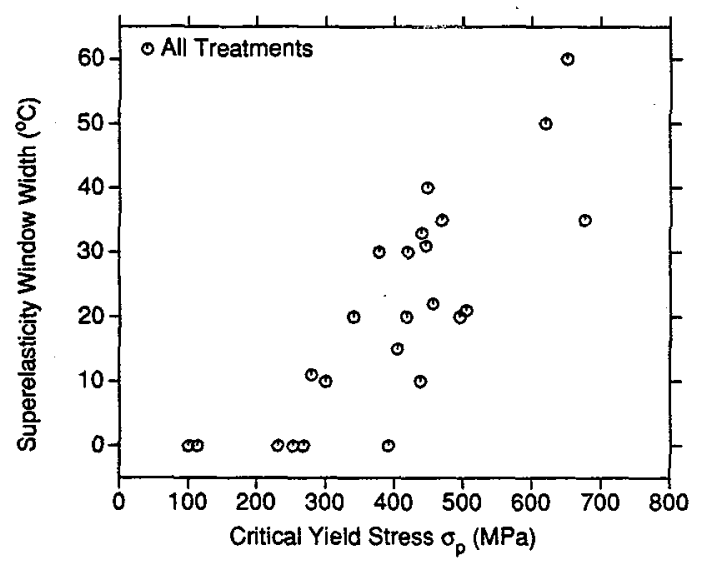

Fig.4 Relationship between superelasticity temperature window width and critical yield stress

Using the least square method, the stress rate $\mathrm{d} \sigma / \mathrm{dT}$ can be calculated from the raw data collected for Ti-Ni alloys. Although not evident for all batches a decrease in do/dT with increasing Ni content is in general observed. Connecting stress rate with window width of SE, it can be observed that batches with low $\mathrm{d} \sigma / \mathrm{dT}$ have high window widths and batches with high $\mathrm{d} \sigma / \mathrm{dT}\left(8 \sim 10 \mathrm{MPa} /{ }^{\circ} \mathrm{C}\right)$ have no SE behaviour. The results for annealed specimens are shown in Fig.5. It should be noted that for solution and ageing treatments, some lower do/dT batches have zero window width of SE. This is because SE behaviour is restricted by both $\sigma_{p}$ and $d \sigma / \mathrm{dT}$ but the former plays a more important role. In fact these lower $d \sigma / \mathrm{dT}$ batches showing no $\mathrm{SE}$ behaviour correspond to $\sigma_{\mathrm{p}}<300 \mathrm{MPa}$.

Good SE behaviour is almost always associated with intermediate $\mathrm{R}$-phase and presence of precipitates by ageing and/or dislocations rearranged by annealing after cold work, see Table 2 . For Ti-Ni alloys without SE behaviour, there is neither $R$-phase nor internal fine structure present. The relationship between the $S E$ window width of $S E$ and the difference $T_{c}-A_{f}$ is straightforward: i) the window width of $S E$ is equal to zero if $T_{c}<A_{f}$; ii) the window width increases with increasing the difference $T_{c}-A_{f}$, as indicated in Fig.6. This can be well understood by considering the fact that $S E$ behaviour occurs in the temperature region $\left(\mathrm{A}_{\mathrm{f}}<\mathrm{T}<\mathrm{T} \mathrm{c}\right)$.

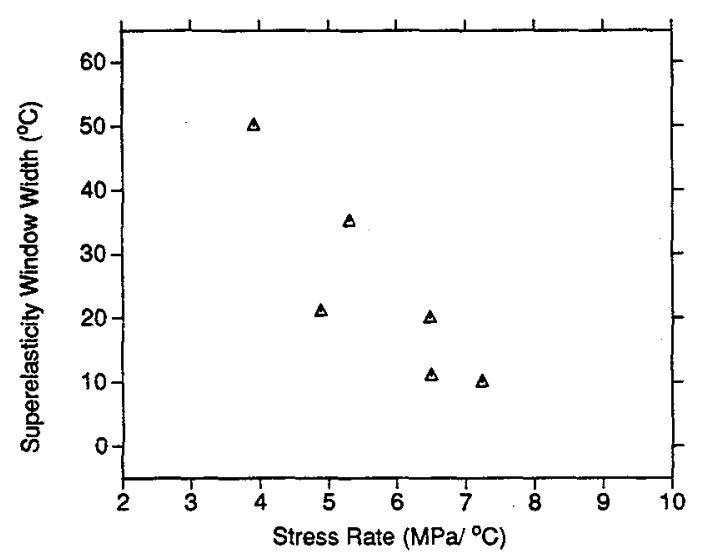

Fig. 5 Influence of stress rate on superelasticity temperature window width of annealed specimens

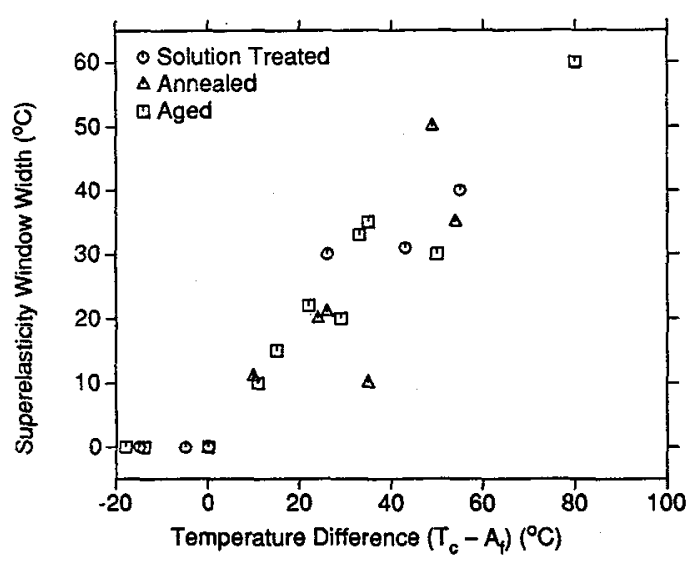

Fig. 6 Dependence of superelasticity temperature window width on the difference between the critical temperature $T_{c}$ and transformation temperature $A_{4}$ 
Table 2. Examples of Relations Between Property Data and Microstructure

\begin{tabular}{|c|c|c|c|c|c|c|c|c|}
\hline Material & Data Set & $\begin{array}{l}\text { Trans formation } \\
\text { Temp. Af }\left({ }^{\circ} \mathrm{C}\right)\end{array}$ & $\begin{array}{l}\text { Critical } \\
\text { Temp. Tc }\left({ }^{\circ} \mathrm{C}\right)\end{array}$ & $\begin{array}{l}\text { Critical } \\
\text { Stress (MPa) }\end{array}$ & $\begin{array}{l}\text { SE Window } \\
\text { Width }\left({ }^{\circ} \mathrm{C}\right)\end{array}$ & $\begin{array}{l}\text { Stress } \\
\text { Rate }\left(\mathrm{MPa} /{ }^{\circ} \mathrm{C}\right)\end{array}$ & \multirow[t]{2}{*}{ R-Phase } & \multirow[t]{2}{*}{$\begin{array}{l}\text { Internal } \\
\text { structure }\end{array}$} \\
\hline \multirow[t]{7}{*}{$\mathrm{TI} 49.8 \mathrm{NI}$} & 1 & 31 & 16 & 113 & o & 4.82 & & \\
\hline & 2 & 34 & 44 & 279 & 11 & 6.50 & RHOMBOH & DISLO REARRANGE \\
\hline & 3 & 40 & 64 & 495 & 20 & 6.47 & RHOMBOH & DISLO REARRANGE \\
\hline & 4 & 45 & 31 & 100 & 0 & 5.70 & & \\
\hline & 5 & 37 & 72 & 437 & 10 & 7.24 & RHOMBOH & DISLO REARRANGE \\
\hline & 6 & 30 & 84 & 675 & 35 & 5.30 & RHOMBOH & DISLO REARRANGE \\
\hline & 7 & 40 & 66 & 504 & 21 & 4.88 & RHOMBOH & DISLO REARRANGE \\
\hline TI50.1NI & 1 & 30 & 12 & 230 & 0 & 4.59 & & \\
\hline \multirow{2}{*}{$\mathrm{T} 150.4 \mathrm{NI}$} & 1 & 40 & 40 & 267 & 0 & 8.67 & & \\
\hline & 2 & 40 & 40 & 251 & 0 & 9.36 & & \\
\hline$T 150.5 \mathrm{NI}$ & 1 & & 70 & 416 & 20 & 6.84 & & \\
\hline \multirow[t]{6}{*}{$\mathrm{TI50} .6 \mathrm{NI}$} & 5 & 22 & 33 & 300 & 10 & 4.15 & RHOMBOH & FINE PRECIPIT \\
\hline & 6 & 5 & 40 & 469 & 35 & 4.27 & RHOMBOH & FINE PRECIPIT \\
\hline & 7 & -34 & -5 & 340 & 20 & 3.63 & & \\
\hline & 6 & 11 & 60 & 620 & 50 & 3.92 & RHOMBOH & PRECI_DISLO \\
\hline & 9 & $\theta$ & 41 & 440 & 33 & 3.99 & RHOKBOH & FINE PRECIPIT \\
\hline & 10 & -52 & -9 & 446 & 31 & 6.32 & & \\
\hline TI50NI & 1 & 110 & 105 & 390 & 0 & 9.45 & & \\
\hline \multirow[t]{4}{*}{$T I 51.3 \mathrm{~N} I$} & 1 & -75 & -20 & 447 & 40 & 6.86 & & \\
\hline & 2 & -70 & -20 & 378 & 30 & 5.01 & & \\
\hline & 3 & -25 & -10 & 404 & 15 & 6.75 & & \\
\hline & 4 & 23 & 45 & 455 & 22 & 7.60 & $\mathrm{RHOMBOH}$ & WIDMANSTATTEN \\
\hline TI51.6NI & 1 & -23 & 57 & 650 & -60 & 4.19 & RHOMBOH & FINE PRECIPIT \\
\hline TI5INI & 1 & -40 & -14 & 420 & 30 & 3.85 & & \\
\hline
\end{tabular}

SE: Superelasticity

DISLO REARRANGE: Dislocation Rearrangement

FINE PRECIPIT: Fine Precipitates

RHOMBOH: Rhombohedral Structure

PRECI_DIS REARRANGE: Precipitates and Dislocation Rearrangement

\section{Acknowledgements}

Financial support from the National Swedish Board for Technical Development is gratefully acknowledged. One of the authors would like to express thanks to colleagues Mr.Laizhe Jin et al for their help.

\section{References}

1. Sandström R., Lagneborg R., Scand. J. Metall., 17(1988)108.

2. Rumble J.R., Smith F.J., Database Systems in Science and Engineering, Hilger, Bristol(1990).

3. Sandström R., Ivarsson B., Lindblom J., ASTM STP 1106, Computerization and Networking of Materials

Data Bases, Kaufman J.G. and Glazman J.S., Eds. Vol.2(1991)214-229.

4. Funakubo H., Shape Memory Alloy, Gordon \& Breach Science Publishers, New York, 1987

5. Duering T.W., Melton K.N., Stöckel D., and Wayman C.W., Engineering Aspects of Shape Memory Alloys, Butterworth-Heinemann, London, 1990.

6. Miyazaky S., Otsuka K., and Suzuki Y., Scripta Metall. 15(1981)287.

7. Warliment H., Delaey L., Krisknan R.V., and Tas H., J. Mater. Sci. 9(1974)1545.

8. Wasilewski R.J., Bulter S.R., Hanlon J.E., and Worden D., Met. Trans. 22(1971)229.

9. Miyazaky S., Ohmi Y., Otsuka K., and Suzuki Y., J. de Phys. 43, No.-Suppl. (1982)C4-255.

10. Saburi T., Tatsumi T., and Nemo S., J. de Phys. 43, No.-Suppl. (1982)C4-261. 